\title{
Hacer política en un pueblo azucarero: prácticas a ras del suelo en la transición del radicalismo al peronismo. Bella Vista (Argentina)*/
}

\section{Doing politics in a sugar community: grassroots practices in the transition from Radicalism to Peronism. Bella Vista (Argentina)}

\author{
Leandro Lichtmajer \\ ORCID iD: http://orcid.org/0000-0003-1349-4444 \\ Florencia Gutiérrez \\ ORCID iD: http://orcid.org/0000-0001-8659-0598
}

Instituto Superior de Estudios Sociales (UNT-CONICET)

El objetivo del artículo es analizar las prácticas políticas en el pueblo azucarero de Bella Vista (Argentina) en la transición del radicalismo al peronismo (1935-1946). En este sentido, estudia la reconfiguración de las redes partidarias locales, la transformación de los liderazgos y sus anclajes sociales, así como la articulación de organizaciones de base que moldearon las formas de hacer política en una coyuntura clave de la historia argentina del siglo veinte.

Palabras clave: Prácticas Políticas; Radicalismo; Peronismo; Pueblos Azucareros.

The aim of this paper is to analyze the political practices in the sugar community of Bella Vista (Argentina) in the transition from Radicalism to Peronism (1935-1946). In this sense, studies the reconfiguration of the local party networks, the transformation of the leadership and their social foundations, as well as the articulation of grassroots organizations that have shaped the ways of doing politics in an important conjuncture in the Argentina history of the twentieth century.

Keywords: Political Practices; Radicalism; Peronism; Sugar Communities.

Copyright: (C) 2017 CSIC. Este es un artículo de acceso abierto distribuido bajo los términos de una licencia de uso y distribución Creative Commons Attribution (CC-by) España 3.0.

* Este artículo se desarrolló en el marco del Programa de Investigación «Estado, economía y sociedad en Tucumán. Un enfoque de larga duración, siglos XIX-XX», financiado por la Secretaría de Ciencia, Arte e Innovación Tecnológica de la Universidad Nacional de Tucumán (código H552/1). Una versión preliminar del texto fue discutida en el Seminario Interinstitucional de Historia Política, Instituto Mora (México) dirigido por Fausta Gantús y Alicia Salmerón. Agradecemos los comentarios recibidos en esa oportunidad. También destacamos las observaciones que realizó Mark Healey al borrador del artículo y la generosidad de Manuel Valeros, quien nos brindó documentación de utilidad. 
En octubre de 1942 Manuel García Fernández, propietario del ingenio Bella Vista (Tucumán) ${ }^{1}$ y presidente de la Unión Cívica Radical (UCR) ${ }^{2}$ de esa provincia, celebró el triunfo electoral del candidato a gobernador de su partido. Sostuvo que la victoria de la UCR en Famaillá, departamento en el que se radicaba el establecimiento fabril, demostraba «que la fuerza que hemos constituido no se ha desconectado de la masa radical sino que, por el contrario, ha consultado sus orientaciones». ${ }^{3}$ Sin duda, parte sustancial de la fuerza constituida remitía al liderazgo político que fraguó en el pueblo aledaño al ingenio, donde logró articular una densa trama relacional permeada por los vínculos productivos agroindustriales y volcada masivamente al radicalismo. El triunfo en el circuito Bella Vista ${ }^{4}$ fue elocuente, los 1.749 votos alcanzados por esta fuerza lo distanciaba de los 494 obtenidos por el Partido Demócrata Nacional (PDN), a cargo del gobierno nacional, y los 257 votos del Partido Socialista (PS). ${ }^{5}$ Hombre acostumbrado a las victorias, nada le hacía prever su inminente retiro de la política y el ciclo de derrotas radicales que se avecinaba. El golpe de Estado de junio de 1943 significó un paréntesis en la vida institucional. Posteriormente, la irrupción del peronismo implicó una sensible transformación en las lealtades políticas de la sociedad bellavisteña. Basta recordar que en las elecciones presidenciales de febrero de 1946 la candidatura de Juan Domingo Perón

1 La provincia de Tucumán se ubica en la región Noroeste de Argentina. En 1947 contaba con 593.371 habitantes. IV Censo General de la Nación, Buenos Aires, Dirección Nacional del Servicio Estadístico, 1947, I, 430-431 (disponible en https://www.santafe.gov.ar/archivos/estadisticas/censos/ censo1947.pdf). El ingenio Bella Vista fue una nítida expresión del desarrollo azucarero tucumano de fines del siglo diecinueve. Campi, 2000. Fue fundado en 1882 por los inmigrantes españoles José y Manuel García Fernández en un paraje ubicado a 25 kilómetros al sudoeste de San Miguel de Tucumán, centro administrativo y comercial de la provincia.

2 La UCR fue fundada en 1891 en oposición al régimen conservador dominado por el Partido Autonomista Nacional. De bases sociales y programáticas heterogéneas, entre sus ejes identitarios pueden destacarse la defensa de las instituciones republicanas y la reivindicación de los derechos establecidos en la Constitución Nacional de 1853. Luego de un período en el que la UCR combinó la política de abstención y participación electoral con el desarrollo de movimientos revolucionarios para derrocar al gobierno conservador, alcanzó el poder en 1916 de la mano de Hipólito Yrigoyen y gobernó el país hasta 1930, cuando este presidente fue desalojado del poder por un golpe de Estado. Rock, 1977.

3 La Gaceta, Tucumán, 13 de octubre de 1942.

4 En términos electorales Tucumán se dividía en 11 departamentos y 130 circuitos. Bella Vista contaba con un total de 2.537 votantes efectivos, lo cual representaba alrededor de un 20 por ciento del departamento Famaillá y un 2 por ciento de Tucumán. La Gaceta, Tucumán, 12 de enero de 1937.

5 El conservador PDN fue fundado en 1931, constituyéndose en una importante fuerza política nacional en la década de 1930. En alianza con los partidos UCR Antipersonalista y Socialista Independiente fundó la Concordancia, de cuyo seno surgieron los presidentes Agustín P. Justo (19321938), Roberto Ortiz (1938-1940) y Ramón Castillo (1940-1943). El Partido Socialista (PS) fue fundado en 1896 y su principal radio de influencia fue la región pampeana. Sobre el rol de ambos partidos en Tucumán véase Parra, 2011; Fernández de Ullivarri, 2011. 
concitó 2.181 sufragios, mientras que la alianza partidaria liderada por la UCR cosechó 286 votos. A fines de los años cuarenta, los recurrentes descalabros comiciales radicales llevaron a un observador a señalar que «ni siquiera los fiscales» votaban por su partido. ${ }^{6}$

Este contrapunto constituye un disparador para reflexionar sobre un conjunto de problemas inscritos en la renovada la historia política argentina de las últimas décadas. En ese sentido, preguntarse por las formas de hacer política en un pueblo azucarero tucumano en la transición entre el radicalismo y el peronismo supone, por un lado, complejizar construcciones asociadas a los dos partidos más importantes de Argentina en el siglo veinte. Al analizar la construcción de redes partidarias y prácticas políticas de la UCR en una localidad agroindustrial del noroeste, el artículo abona a un campo poco transitado por la historiografía, que privilegió el estudio de la expansión radical en clave urbana y pampeana, particularmente para el período 1916-1930. En esta dirección pueden subrayarse los clásicos trabajos de David Rock (1977) y Joel Horowitz (2007) sobre las redes partidarias en la capital federal y su articulación con las formas de patronazgo desplegadas por el Estado y asociadas al otorgamiento de empleos públicos. Entendemos que las preocupaciones que guían este texto contribuyen a comprender las dinámicas y particularidades que asumió la construcción política del radicalismo en zonas agroindustriales, especialmente en las comunidades laborales. Por otro lado, el artículo ofrece aristas para repensar la emergencia del peronismo en el interior del país, en consonancia con las producciones compiladas por Darío Macor y César Tcach (2003), y recuperar el desafío, planteado por Raanan Rein (2009), de transitar «de los grandes relatos a los estudios de pequeña escala». En efecto, el análisis de la trayectoria del peronismo en Bella Vista permite ponderar la fuerte impronta sindical en el despegue y consolidación del movimiento, en contraste con la gravitación que el radicalismo y el conservadurismo tuvieron en otras latitudes. Esta marca de origen posibilita escudriñar, entre otros tópicos, las tensiones asociadas a la construcción de nuevos liderazgos, las aspiraciones de exclusivismo político impulsadas por el naciente gremialismo, las disputas por el control partidario desatadas con otros actores, así como los canales de resolución de la conflictividad local.

En segunda instancia, la reducción de la escala de observación y la perspectiva «a ras del suelo» ${ }^{7}$ procura desandar construcciones que

6 Trópico, Tucumán, 15 de marzo de 1948.

7 Revel, 1989. 
asociaron la política en las comunidades laborales como «una consecuencia automática de las relaciones de lealtad y obediencia derivadas directamente de las relaciones de producción», ${ }^{8}$ al tiempo que permite indagar cómo la dinámica local se «redefine y se ve redefinida por los cambios y permanencias de ese universo macro en cuyas tramas se referencia». ${ }^{9}$ Esta mirada centrada en los actores y las prácticas constituye una privilegiada estrategia metodológica para acercarnos a la construcción social del poder y las formas cotidianas de hacer política.

La elección del recorte temporal, en el tránsito del radicalismo al peronismo, permite analizar la reconfiguración de las redes partidarias locales, la transformación de los liderazgos y sus anclajes sociales, así como la articulación de organizaciones de base que marcaron el pulso de las prácticas y dinámicas políticas. En tal sentido, el artículo argumenta que durante el ciclo de gobiernos radicales en Tucumán (1935-1943) se consolidó en Bella Vista un entramado partidario que, liderado por la patronal, apuntaló la trayectoria política del propietario y algunos empleados jerárquicos e involucró, de diversas formas, a los trabajadores del ingenio. El golpe de Estado de 1943 y, más tarde, el triunfo del peronismo, erosionaron la hegemonía radical y provocaron el repliegue de las redes partidarias vinculadas a la patronal. En ese marco se produjo un reordenamiento de los liderazgos locales y de la dinámica política, asociados al novel protagonismo sindical y a la identificación de la comunidad local con el movimiento liderado por Perón. El afianzamiento político de los obreros y sectores medios engendró niveles de conflictividad que, lejos de representar un signo de debilidad, remitían a un movimiento en franca expansión.

\section{El campo político bellavisteño en los años treinta: la centralidad de las redes lideradas por la patronal}

En 1934 la UCR de Tucumán se convirtió en la primera filial del partido en reincorporarse a la lucha electoral tras el golpe de Estado de 1930, abandonando la estrategia abstencionista adoptada por el Comité Nacional como respuesta a la política hostil del gobierno. ${ }^{10}$ El triunfo de la UCR de Tucumán en las elecciones legislativas y ejecutivas abrió paso a un ciclo de

8 Fradkin y Gelman, 2004, 53.

9 Bonaudo, 2008, 228. Cursivas en el original.

10 Lichtmajer, 2012, 33-36. 
gestiones radicales (1935-1943), que contrastó con un mapa político nacional dominado por la Concordancia.

En ese marco, el propietario del ingenio Bella Vista y sus colaboradores más estrechos participaron activamente en la vida pública y accedieron, a través de la UCR, a puestos de influencia en el mapa político provincial y nacional. En 1923 Manuel García Fernández asumió el mando del establecimiento fabril, en razón del fallecimiento de su progenitor, iniciándose en las lides políticas como diputado provincial por el departamento Famaillá (1922-1930). ${ }^{11}$ Durante el ciclo de gobiernos radicales de los años treinta García Fernández ocupó los cargos de senador — provincial y nacional(1936-1943) y presidente de la UCR (1938-1943), erigiéndose en una figura central del tablero político tucumano. Su principal aliado político fue Arturo Álvarez, administrador del ingenio. Al igual que García Fernández, la trayectoria de Álvarez en el radicalismo se inició durante los años veinte, alcanzando a partir de 1934 un lugar preeminente en la escena política tucumana. ${ }^{12}$ En su carácter de presidente del Senado (1936-1943), primero en la línea de sucesión del gobernador, ejerció interinamente la magistratura provincial en repetidas oportunidades. Ambas trayectorias recuperaban una tradición característica del empresariado azucarero tucumano desde finales del siglo diecinueve, cifrada en la ocupación de puestos de influencia en los partidos, el aparato administrativo provincial y la asunción de cargos parlamentarios nacionales como una vía para la defensa de los intereses industriales y la promoción de medidas asociadas a los departamentos azucareros. ${ }^{13}$

Las carreras políticas de García Fernández y Álvarez tuvieron un anclaje eminentemente local, punto de partida que les permitió proyectarse en la escena provincial y nacional. En este sentido, los lugares de preeminencia social que ostentaron como propietario y administrador del ingenio les permitieron articular un repertorio de prácticas que involucraron a la

11 El sistema político tucumano era bicameral con voto directo, masculino y obligatorio; el gobernador se elegía de manera indirecta, a través de un Colegio Electoral en el que estaban representados los 11 departamentos proporcionalmente a su población, y su mandato tenía una duración de cuatro años. Archivo de la Honorable Legislatura de Tucumán (AHLT), Boletín Oficial de Tucumán, 27 de enero de 1916, 241-48.

12 Fue senador provincial en varios períodos (1924-1930, 1934-1943).

13 Guy, 2008. Durante las décadas 1920-1930 la presencia de diputados y senadores bellavisteños gravitó en la articulación de proyectos y medidas legislativas tendientes a fortalecer la infraestructura de la villa. Asimismo, su presencia se volcó hacia la defensa de los intereses corporativos. Por ejemplo, en 1934 el senador Álvarez se opuso a un impuesto al azúcar y en 1939 promovió la suspensión de la ley que establecía la asistencia médica en los ingenios. Diario de Sesiones de la Cámara de Senadores de la Provincia de Tucumán (DSCST), 1924, 91; 1934, 37; 1935, 79; 1939, 74. 
comunidad bellavisteña en diferentes formas e instancias de la política. ${ }^{14}$ Como un profeta en su tierra, García Fernández construyó una densa red social modelada por la impronta de las jerarquías socio-laborales características del pueblo azucarero. Por su parte, las funciones que asumió Álvarez en la estructura laboral del ingenio coadyuvaron al afianzamiento de su carrera política. Como director del hospital (1916-1930) desempeñó un rol destacado en la sociedad bellavisteña, su función no solo se limitaba a velar por la salud de obreros y empleados, también intervenía en el otorgamiento de licencias, pensiones y otros beneficios proporcionados por el ingenio a sus trabajadores. Como administrador (1930-1943) representó la cara visible de la patronal frente a los dependientes de la fábrica y los vecinos del pueblo. En los ingenios «todas las funciones de coordinación y contralor fluían de forma ascendente hacia la cabeza del establecimiento» representada por el administrador, quien contaba con la colaboración de jefes de fabricación y cultivo, mayordomos y capataces ${ }^{15} \mathrm{El}$ administrador sintetizaba la presencia e intereses del propietario en la cotidianeidad laboral y comunitaria, era el encargado de supervisar los procesos y ritmos productivos y coadyuvar al sostenimiento del orden social.

Concomitantemente a estos roles, Álvarez lideró ámbitos de sociabilidad obrera organizados desde la patronal con el fin de promover formas de ocio y modelar sentidos de pertenencia asociados al ingenio. En los años treinta fue presidente de los clubes Social de Empleados y Obreros y Sportivo Bella Vista. El primero encarnaba el lugar de reunión por antonomasia de las familias acomodadas de la comunidad (empleados jerárquicos y obreros calificados, comerciantes, funcionarios locales), destinado a actividades recreativas (cartas, billar), funciones de teatro, bailes y eventos sociales de diferente índole. Este espacio de matriz excluyente convivió con otros de mayor integración comunitaria. Tal fue el caso del club Sportivo, dedicado a la práctica de diversos deportes y juegos (fútbol, básquet, bochas, palitroque), el cual fue alentado por García Fernández a través de donaciones de tierras y contribuciones monetarias y fue sostenido con los descuentos aplicados al salario de los trabajadores. En su plantel futbolístico, cuyo distintivo rojo y blanco recuperaba los colores tradicionales de la

14 Los pueblos azucareros configuraron comunidades laborales jerarquizadas y contrastantes. En la cima de la pirámide socio-laboral se ubicaban el propietario y el administrador del ingenio, secundados por empleados jerárquicos, técnicos y personal administrativo. Más abajo se hallaban los obreros permanentes, ya fueran de fábrica o surco. El último eslabón de la cadena productiva eran los obreros temporarios. Campi, 2009, 254.

15 Moyano, 2011, 98. 
UCR, se entremezclaron obreros, empleados y jugadores contratados por el establecimiento, impronta policlasista refrendada con la asistencia masiva a sus presentaciones. ${ }^{16}$

Centradas en García Fernández y Álvarez, las redes de interacción política lideradas por la patronal involucraron un denso entramado de actores, provenientes mayoritariamente de la estructura laboral azucarera. Con diferentes grados de responsabilidad, empleados del ingenio y arrendatarios de tierras propiedad de la fábrica se sumaron al radicalismo y participaron activamente en la vida política local y provincial entre 1934 y $1943 .{ }^{17}$ Asimismo, un conjunto importante de empleados del ingenio activaron centros y comités ${ }^{18}$ del partido en Bella Vista y los circuitos electorales aledaños, alrededor de la mitad de ellos militaron en diferentes instancias del radicalismo a lo largo de la década de $1930 .{ }^{19}$ Esta capilaridad política los involucró, con disímiles grados de compromiso, en las faenas preelectorales y la dinámica asociativa local. Superando los márgenes de la comunidad laboral azucarera, pero en estrecha vinculación con ella, también identificamos numerosos actores de la sociedad local (comerciantes, empleados de actividades terciarias) que participaron en el entramado partidario de la mano de García Fernández y Álvarez. ${ }^{20}$

La urdimbre liderada por el propietario del ingenio se potenció a través de la alianza con los poderes públicos locales, hecho que gravitó en la dinámica política bellavisteña. En consonancia con lo señalado para otras comunidades laborales de Argentina, ${ }^{21}$ los representantes del Estado en los pueblos azucareros solían erigirse en aliados estratégicos de los empresarios a la hora de arbitrar en los conflictos locales y prestar su colaboración en tareas ajenas a su función pública, tales como el proselitismo político. Contar con un comisario aliado implicó, por ejemplo, valerse de la fuerza

16 Valeros y Salazar, 2012, 335.

17 Manuel Heredia (arrendatario, diputado provincial 1935-1942), Julio César Romano (médico, senador provincial 1934-1936), Juan Carlos Guyot (gerente, diputado provincial 1935-1943), Francisco López García (procurador, diputado provincial 1935-1941); Aurelio Romero (empleado jerárquico, convencional partidario 1942); Ramón Castro (empleado jerárquico, convencional partidario 1941).

18 Las denominaciones de centros y comités se utilizaban indistintamente para aludir a organismos locales de la UCR, que se creaban mayoritariamente en épocas preelectorales y desarrollaban un amplio espectro de prácticas de reclutamiento, movilización y proselitismo. Unión Cívica Radical, 1941, 7-9.

19 Empleados superiores del ingenio, 1939, Archivo Privado de Antonio Ramón Zelarayán (APARZ), Bella Vista, Compañía azucarera Bella Vista.

20 Julio César Valdez (comerciante), Ángel C. Zelaya (empleado ferroviario).

21 Kindgard, 2009; Bohoslavsky y Caminotti, 2003. 
pública para sofocar protestas obreras, como sucedió en junio de 1919 en el ingenio Bella Vista. ${ }^{22}$ Por el contrario, la presencia de funcionarios adversos al signo político del industrial generó conflictos, como sucedió en el ingenio San Juan, cuyo propietario, enrolado en el radicalismo, denunció que el comisario intimidaba a los votantes en razón del «compromiso» asumido con un partido rival. ${ }^{23}$

Cabe señalar que la presencia de funcionarios locales (comisario, juez de paz, comisionado de higiene y fomento) afines a los intereses del establecimiento dependía de la buena voluntad de las autoridades provinciales, quienes controlaban las designaciones. ${ }^{24}$ De allí que la patronal bellavisteña no escatimara recursos ni gestiones a la hora de obtener el favor estatal en los nombramientos, como se desprende de la correspondencia entablada entre Manuel García Fernández y su padre en $1919 .{ }^{25}$ Desde 1935, la influencia de la patronal en el gobierno radical le aseguró la presencia de funcionarios afines, quienes colaboraron en las tareas electorales. ${ }^{26}$ En respuesta, los partidos opositores denunciaron que el comisario del pueblo y sus colaboradores se «hallaban entregados» al radicalismo en la campaña electoral de octubre de 1942, connivencia que los llevaba a intimidar a los dirigentes opositores y tolerar prácticas de juego clandestino y episodios de violencia protagonizados por los radicales. ${ }^{27}$

Las redes lideradas por la patronal también se proyectaron en las actividades y dinámica de los centros y comités partidarios, que visibilizaron la relevancia de García Fernández y sus allegados en la política bellavisteña.

22 Manuel García Fernández (hijo) a Manuel García Fernández, Bella Vista, 4 de junio de 1919, Archivo del Centro Cultural Alberto Rougés (ACCR).

23 Informe del Gral. de Brigada don Luis A. Cassinelli con motivo de las funciones de observador oficial del Poder Ejecutivo Nacional durante las elecciones del 4 de marzo de 1934 en la provincia de Tucumán. Archivo General de la Nación (AGN), Fondo del General Justo, Caja 62, Carpeta C, 137.

24 Los jueces de paz, designados por el poder ejecutivo provincial, intervenían en casos judiciales, controlaban el registro civil y autorizaban la matrícula de los comerciantes, entre otras funciones. Los comisionados representaban al gobierno provincial en las poblaciones menores a 4.000 habitantes. Cumplían funciones de salubridad, higiene y asistencia pública, urbanización y fomento a la cultura. Ley Orgánica de los Tribunales de Justicia n. ${ }^{\circ}$ 957, 1908; Ley de Comisiones de Higiene y Fomento n. ${ }^{\circ}$ 1210, 1917, AHLT, Digesto Jurídico de la Provincia de Tucumán.

25 Manuel García Fernández (hijo) a Manuel García Fernández, Bella Vista, 11 de junio de 1919, ACCR. «En estos días anduve en conferencias con una cantidad de personas (Jefe de Policía, Ministros, industriales, etc.) y he conseguido que lo manden a Rodríguez López de comisario».

26 Felipe Salto, empleado jerárquico del ingenio y dirigente radical, fue juez de paz en los períodos 1936-1938 y 1943-1944. Listado de jueces de paz de Bella Vista (1902-1991), Archivo Privado de Manuel Valeros (APMV), Tucumán.

27 La Gaceta, Tucumán, 16 de octubre de 1942. 
Como señalamos, una de sus expresiones fue la participación de empleados del ingenio en las comisiones directivas, destacándose, por ejemplo, la presencia de Juan Mena (enfermero del hospital), Ramón Blanco y Ramón Castro (empleados jerárquicos) y Juan de Boeck (obrero calificado). Nos detendremos en Mena, en tanto sintetiza el nexo entre la jerarquía laboral y la actividad política liderada por la patronal. Como enfermero del ingenio, Mena se relacionaba estrechamente con los médicos y el director del nosocomio bellavisteño, representantes de los propietarios, y con los trabajadores de la fábrica y de las colonias agrícolas ubicadas en la periferia del pueblo. Sus actividades en el hospital y las dispensadas en su domicilio particular, situado en los lindes del casco urbano de Bella Vista, lo vinculaban cotidianamente con obreros, empleados y vecinos del pueblo. En efecto, la residencia particular de Mena fue un punto de reunión para los bellavisteños y sede habitual de comités radicales, lo cual se explica por la naturaleza de su labor profesional y por las características de su vivienda, que poseía un terreno extenso dotado de una parrilla y un espacio destinado a la práctica de la taba y las bochas, entretenimientos populares de gran difusión en el mundo rural. ${ }^{28}$ Su posición estratégica en la comunidad y sus lazos con la patronal potenciaron la participación de Mena en la dinámica política local: presidió comités del partido en las campañas de 1934 y 1937 y fue electo convencional provincial ${ }^{29}$ por el departamento Famaillá (1942). ${ }^{30}$ La trayectoria de Mena puede interpretarse en consonancia con la caracterización de Mirta Lobato sobre la comunidad obrera de Berisso (Buenos Aires), donde médicos y abogados «ayudaban a mantener los lazos políticos con la población en su conjunto y con los obreros» ofreciendo servicios que constituían un camino «para forjar adhesiones y lealtades» partidarias. ${ }^{31}$

Otra variable que reafirmó la centralidad política del industrial y sus allegados se expresó en las denominaciones de algunos comités, que fueron bautizados con los nombres de García Fernández, Álvarez y Julio César Romano (médico del hospital y dirigente radical). ${ }^{32}$ Además de escenificar un reconocimiento y adhesión simbólica a figuras representativas de

28 Entrevista a Manuel Valeros realizada por Leandro Lichtmajer, Tucumán, 3 de junio de 2013.

29 La Convención Provincial, formada por delegados de los departamentos, era el órgano máximo del partido en la provincia. Unión Cívica Radical, 1941, 1-2.

30 El Orden, Tucumán, 28 de septiembre de 1934 y 14 de diciembre de 1937.

31 Lobato, 2004, 231.

32 En las elecciones de 1938 y 1942 llevaron dichas designaciones seis comités. El Orden, 30 de septiembre de 1938. La Gaceta, Tucumán, 1 de febrero de 1942. 
la comunidad, es factible explicar estos nombramientos con razones más pedestres, como el patrocinio económico brindado a las entidades. A este argumento abona la inclusión sistemática de García Fernández, Álvarez y otros empleados jerárquicos del ingenio en las comisiones honorarias, actitud que refrendaba el reconocimiento a los impulsores y sostenedores materiales de los comités. ${ }^{33}$

La participación de los trabajadores en las redes partidarias tendió a ubicarse en un plano activo pero subalterno. La dinámica política reprodujo, con matices, el paternalismo que caracterizó la relación entre la patronal y la comunidad laboral; ${ }^{34}$ como contrapunto, el conjunto obrero pudo canalizar expectativas y demandas. ${ }^{35}$ En este contexto de preocupaciones, la integración de los trabajadores en el entramado radical bellavisteño fue alentada: algunos obreros calificados ocuparon puestos intermedios en la estructura partidaria, como miembros de los comités o convencionales provinciales. ${ }^{36}$ Por otro lado, el conjunto obrero nutrió los actos partidarios y electoralistas, como sucedió en la reunión que el comité « 4 de febrero» realizó en Bella Vista en 1934, en la que se ofreció a los concurrentes un «asado con cuero», o su presencia en la carrera de ciclistas organizada en 1942 por el centro «Arturo R. Álvarez». ${ }^{37}$

Finalmente, la movilización de contingentes obreros el día de las elecciones constituía un eslabón en la cadena de prácticas partidarias y comiciales que, organizadas por la patronal, se nutrían de las relaciones paternalistas. Un trabajador permanente del ingenio, Fronterita, refería que durante las campañas electorales de los años treinta «se reunía la gente en el comité [...] el día de las elecciones ahí estaban. Daban, ponían autos para votar porque había unas escuelas que estaban retiradas de ahí. Entonces daban plata. Daban tres pesos por voto: dos de ida y uno cuando volvían con la libreta». ${ }^{38}$ Por su parte, fracciones radicales contrarias a García Fernández

33 Lichtmajer, 2014, 84.

34 En el caso del Bella Vista, la construcción de casas, las prestaciones sociales, la fundación de escuelas y la instalación de una olla infantil expresaron el paternalismo de García Fernández. Por su parte, la proveeduría, el sistema de vales, el control del tiempo libre y del asociacionismo y la represión de la protesta obrera revelaron la faz coactiva de esta impronta empresarial. Lichtmajer, Gutiérrez y Santos Lepera, 2016. Sobre el paternalismo de los empresarios azucareros remitimos a Bravo, 2000, y Landaburu, 2014.

35 Remitimos al texto de Eduardo Posada Carbó (2000, 630), particularmente sus apreciaciones sobre la relación entre paternalismo y participación electoral.

36 Juan Coronel (autoridad de comités en 1934-1937, convencional provincial en 1942); José Leguizamón (autoridad de comité en 1942); Juan de Boeck (autoridad de comité en 1942).

37 El Orden, Tucumán, 3 de octubre de 1934. La Gaceta, Tucumán, 22 de enero de 1942.

38 Taboada y Lobo, 1996, 82. 
denunciaron las maniobras de este en un acto de campaña realizado en San Miguel de Tucumán en 1934. Lo acusaron de «hacer desfilar» a «la gente mandada de Bella Vista» tras ofrecerles un «preludio de beberajes en algunos comités de la ciudad y tabeadas». Así, aunque el ingenio pagaba «salarios de hambre, sin asistencia social», a cambio del voto proporcionaba una «jornada de turismo urbano» a los trabajadores del establecimiento. ${ }^{39}$

Si bien esta caracterización, surgida al calor de la disputa entre las fracciones radicales, enfatiza el rol pasivo de los trabajadores, restándoles capacidad de agencia, cabe señalar que las múltiples implicancias de la política electoral suponían expectativas de reciprocidad que encontraban en los comicios una oportunidad para expresarse. El triunfo radical en las urnas, al tiempo que revelaba el dinamismo de las relaciones paternalistas, habilitaba a los trabajadores un espacio de negociación avalado por los favorables resultados electorales. En efecto, los comicios articulaban demandas obreras y los escaños legislativos generaban promesas que podían plasmarse en mejoras para el pueblo: plazas, mercados, bibliotecas y estaciones sanitarias materializaban los alcances de la reciprocidad. Desde la perspectiva de García Fernández, su participación política procuraba la defensa de los intereses de la industria, en general, y de la comunidad bellavisteña, en particular. En 1934 afirmó que «era industrial y se honraba en serlo dado que se complacía en declarar que, como tal, había cumplido con los trabajadores del surco dándoles buen salario, instituciones culturales, habitación higiénica, hospital y alimento digno con el concepto de que tal era no solo un deber sino una obligación».. ${ }^{40}$ Delineaba, de ese modo, una suerte de tutela política de los trabajadores que, en consonancia con la reivindicación del paternalismo empresarial, procuraba diferenciarse de las prácticas de los industriales conservadores enrolados en el Partido Demócrata Nacional (PDN), a las que atribuía un carácter regresivo y coactivo. ${ }^{41}$

La configuración de un imaginario que discriminaba las políticas de los industriales radicales y conservadores fue planteada por Ramón Paz Posse, empresario azucarero aliado a García Fernández. Desde su punto de vista, mientras los propietarios radicales ponían «todo su empeño» en mejorar las condiciones de vida de los trabajadores a través del «estricto cumplimiento» de las leyes sociales y la mejora en las condiciones de vida, los conservadores se empecinaban en mantener una «situación denigrante»

39 Adelante, Tucumán, 14 de diciembre de 1934.

40 La Gaceta, Tucumán, 25 de febrero de 1934.

41 Ibidem, 17 de octubre de 1942. Sobre el rol de los industriales en el PDN véase Parra, 2011. 
para la clase obrera ${ }^{42}$ La defensa del rol tutelar de los industriales radicales y su reivindicación frente a sus pares conservadores sintetizaba una autorrepresentación que les atribuía un papel protagónico y enfatizaba la armonía entre los actores azucareros. Cabe suponer que esta representación se asentaba en los guarismos electorales, que refrendaban periódicamente el liderazgo político de los industriales radicales.

En efecto, los dispositivos señalados afianzaron una aceitada maquinaria electoral que erigió a Bella Vista en un núcleo radical insoslayable de la provincia. En las elecciones internas de la UCR (mayo de 1934) participaron 1.268 vecinos del circuito y zonas aledañas. Esta cifra representaba un 50 por ciento de los votantes efectivos en los comicios generales, evidenciando que una de cada dos personas que participaban en las elecciones pertenecía formalmente a la UCR.$^{43}$ El volumen de votantes remitía, asimismo, a la capacidad de movilización del partido a nivel local y a la relevancia del circuito en las filas partidarias de Famaillá y del territorio provincial, ya que en Bella Vista se concentraba la mitad de los afiliados radicales del departamento y un 6 por ciento del total de Tucumán. Como es de suponerse, el marcado predominio radical confinó a los demás partidos a un lugar minoritario del mapa político local. El principal contendiente era el PDN, dominado en Bella Vista por un grupo de comerciantes acomodados y productores cañeros. ${ }^{44}$ Las demás entidades (PS, Partido Agrario) contaron con una influencia limitada. Los porcentajes favorables al radicalismo en las elecciones legislativas y de gobernador desarrolladas en 1934, 1938 y 1942 oscilaron entre un 67 y un 82 por ciento, seguido por el PDN (entre 12 y 19 por ciento) y el PS (entre 4 y 10 por ciento). Estos triunfos electorales ubicaron a la UCR bellavisteña por encima del promedio de votos alcanzado por las listas radicales en el departamento Famaillá y en la provincia. ${ }^{45}$

El electorado local reveló una fuerte fidelidad a las orientaciones políticas del industrial y sus lugartenientes. En los comicios presidenciales de 1937 García Fernández llamó a votar en blanco en señal de protesta por la falta de consenso que obtuvo, dentro del partido, su estrategia de apoyar al candidato de la Concordancia (Roberto Ortiz), coalición enfrentada con la

42 El Orden, Tucumán, 12 de noviembre de 1934.

43 Las cifras del total de votantes corresponden a los comicios de 1937. La Gaceta, Tucumán, 12 de enero de 1937.

44 José Gabino Núñez, Pedro Galante, Fernando Juri, Roque Bustos. La Unión, Tucumán, 16 de enero de 1943.

45 El Orden, Tucumán, 22 de diciembre de 1934. Libro de recortes de las elecciones del 6 de marzo de 1938, 138, AHLT. La Gaceta, Tucumán, 23 de octubre de 1942. 
UCR a nivel nacional. Esta tesitura se impuso en el circuito bellavisteño, alcanzando un 50 por ciento de los votos, contra un 26 por ciento de la lista radical. ${ }^{46} \mathrm{Si}$ bien el porcentaje de votos en blanco se ubicó algunos puntos por debajo de las candidaturas de la UCR en los comicios de los años previos, su predominio indica que, para gran parte del electorado bellavisteño, el sentido de pertenencia a las redes locales del industrial era más potente que la identificación, un tanto más difusa, con los candidatos nacionales del radicalismo.

\section{La reconfiguración de la política: repliegue industrial y avance obrero}

El golpe de Estado de 1943 impuso novedades en las coordenadas políticas nacionales y provinciales, desencadenando múltiples transformaciones en el ámbito bellavisteño. La intervención federal a Tucumán, decretada por el presidente conservador Ramón Castillo en enero de ese año, puso fin al ciclo de gobiernos radicales, abriendo paso a un breve interregno del PDN. Cinco meses más tarde, el golpe militar abrió una nueva etapa que repercutió en la dinámica local, poniendo en jaque la urdimbre política tejida por García Fernández durante los años treinta.

En ese marco, una de las innovaciones fue la avanzada de la sindicalización obrera, alentada por la Secretaría de Trabajo y Previsión que, liderada por Juan Domingo Perón, impactó profundamente en la comunidad bellavisteña. La fundación de sindicatos de base se propagó de forma vertiginosa por los ingenios tucumanos. En enero de 1944 un centenar de obreros del Bella Vista, evadiendo la mirada de la patronal, organizaron una reunión para fundar su sindicato. Este nuevo factor de poder local gravitó en las relaciones con la patronal, transformando la dinámica del pueblo y las formas de hacer política. La nueva presencia tutelar del Estado también se expresó en el reconocimiento de postergados derechos laborales, interpelando las relaciones paternalistas de las comunidades azucareras y cuestionando las prerrogativas de los industriales. La politización se acentuó con la irrupción del peronismo, movimiento que redimensionó las prácticas de los pueblos al incentivar la participación obrera y promover la llegada de nuevos actores a la escena provincial y nacional. Como se observará, estas novedades implicaron el repliegue de los empresarios, un sustancial retroceso electoral del radicalismo en la geografía azucarera, así como la reformulación de la participación política de los obreros. Asimismo, los cambios en

46 Libro de recortes de las elecciones del 5 de septiembre de 1937, 120, AHLT. 
el tablero local posicionaron a dirigentes, hasta ese momento distantes del juego político, particularmente gravitante fue el involucramiento de actores vinculados al funcionariado local y al ámbito comercial.

En junio de 1944 los sindicatos de base fundaron la Federación Obrera Tucumana de la Industria Azucarera (FOTIA), la organización sindical más importante del norte argentino en el período analizado. En virtud del peso cuantitativo de los afiliados bellavisteños - recordemos que este establecimiento era el segundo más importante del país-, el sindicato local se erigió en un engranaje central de la nueva entidad, posición refrendada con la unción de su líder, José Leguizamón, como primer secretario general de FOTIA. La sindicalización bellavisteña recuperó las experiencias de organización previas; las instancias de descontento y resistencia que jalonaron a la comunidad; las formas de solidaridad y reciprocidad obrera forjadas en el proceso de proletarización y las postergadas demandas laborales, que el peronismo desató y articuló con el respaldo estatal. ${ }^{47}$ En ese marco, el sindicato de Bella Vista interpeló diversas prácticas del paternalismo empresarial al replantear el funcionamiento de la olla popular promovida tradicionalmente por García Fernández. En junio de 1945 los trabajadores se preguntaron por qué el patrón tenía que «decir qué da de comer a los hijos de sus obreros [...] nosotros necesitamos trabajo y no olla popular». ${ }^{48}$ Días más tarde, los obreros se manifestaron por las calles del pueblo exigiendo la sustitución del médico de la compañía por mal desempeño de sus funciones y demandaron la renuncia del comisario y un agente de policía, a quienes acusaron de someter a requisas ilegales a los trabajadores involucrándolos en el robo de azúcar. ${ }^{49}$ También discutieron el descuento salarial aplicado por la patronal para el sostenimiento del club Sportivo, finalmente, decidieron que la adhesión era voluntaria y, por tanto, podían renunciar a su condición de socios. ${ }^{50}$

En ese contexto, la vertiginosa consolidación de los sindicatos fue resistida por algunos propietarios mediante diversas estrategias como la de prohibir las reuniones en el perímetro de los establecimientos o cortar el suministro eléctrico durante los actos. Los intentos por frenar el proceso de sindicalización y matizar la conflictividad obrera naufragaron ante el crecimiento exponencial de las organizaciones y por la relevancia que

47 Lichtmajer, Gutiérrez y Santos Lepera, 2016.

48 Acta 21, 17 de junio de 1945, APMV, Libro de Actas del Sindicato de Obreros del Ingenio Bella Vista (1944-1947), 53.

49 La Gaceta, Tucumán, 19 de junio de 1946, p. 9.

50 Acta 11, 30 de mayo de 1944, APMV, Libro de Actas del Sindicato de Obreros del Ingenio Bella Vista (1944-1947), 17. 
alcanzaron los dirigentes gremiales en la arena política. ${ }^{51}$ Los desafíos a la autoridad patronal no se circunscribieron al universo de los trabajadores. En febrero de 1945 se fundó la Federación de Empleados de la Industria Azucarera (FEIA), representativa de las escalas más altas de la pirámide laboral, aquellas que habían tenido una gravitación sustancial en las redes políticas articuladas por la patronal. La sindicalización de los empleados conmovió a los industriales, quienes, frente a la huelga declarada por FEIA en julio de ese año, remarcaron el «daño moral» que implicaba esta medida que, devenida de sus más cercanos colaboradores, quebrantaba «el ambiente de armonía y armoniosa comprensión [...] sin necesidad de apelar a otro arbitrio del que surge de la mutua estima nacida al calor de compartidas tareas». ${ }^{52}$ Este diagnóstico, que atribuía a la conflictividad social generada por la irrupción peronista un debilitamiento de las relaciones paternalistas que habían caracterizado a la comunidad azucarera durante las décadas previas, fue suscripto por García Fernández en diferentes oportunidades. Al desarrollarse la extensa huelga obrera de fines de 1949, que paralizó la actividad productiva por sesenta días, el industrial confesó a su hijo, con un marcado tono de desilusión, que «ya ni mi pueblo me quiere», motivo por el cual tenía que «pegarse un tiro». ${ }^{53}$

La organización gremial de trabajadores y empleados impactó en el mapa de poder local, cuyo vértice organizativo y dinamizador se había cifrado, casi con exclusividad, en García Fernández y sus allegados. En la primera comisión directiva del sindicato de obreros del Bella Vista (19441945) ocuparon lugares protagónicos algunos miembros del entramado político local de los años treinta. Tales fueron los casos de José Leguizamón (presidente), Juan Coronel (vicepresidente), Juan de Boeck (prosecretario), Juan Quesada (tesorero) y Luis Silva (vocal). ${ }^{54}$ Se trataba de segundas o terceras líneas en el mapa de poder, Coronel y de Boeck ocuparon cargos partidarios en el nivel departamental mientras que el resto formó parte de los comités. Por su parte, la organización de los empleados fue liderada por estrechos colaboradores de García Fernández. Por ejemplo, Felipe Salto, juez de paz durante el ciclo de gobiernos radicales de los años treinta, ${ }^{55}$ fue

51 Gutiérrez y Rubinstein, 2012, 296.

52 Schleh, 1947, 439.

53 Entrevista a Manuel Valeros y Antonio Salazar realizada por Agustín García Fernández, Tucumán, 16 de mayo de 2008. Citado en Valeros y Salazar, 2012, 65.

54 Acta 15, 24 de diciembre de 1944, APMV, Libro de Actas del Sindicato de Obreros del Ingenio Bella Vista (1944-1947), 36.

55 Véase nota al pie n. ${ }^{\circ} 26$. 
el delegado del ingenio en la FEIA; mientras que Emilio Navarro, Ramón Castro y Ramón Corbalán, empleados de diferentes escalas y ex miembros de organismos de base radicales, lideraron la filial local de la entidad. ${ }^{56}$

Las transformaciones en el campo político local introducidas a partir del golpe de Estado de 1943 no se limitaron al proceso de agremiación de obreros y empleados. De manera menos estridente que la irrupción de las organizaciones sindicales, el recambio en los planteles de gobierno desarrollado durante el gobierno militar tuvo amplias repercusiones. Como en otros distritos de Argentina, uno de los efectos más perdurables del golpe fue la incorporación de funcionarios en diferentes niveles de la administración pública, quienes nutrirían las filas del naciente movimiento peronista. ${ }^{57}$ En los inicios del gobierno militar los cambios en la burocracia provincial y local se sucedieron incesantemente. Los interventores federales y sus colaboradores abastecieron al aparato estatal de un plantel heterogéneo de dirigentes, propios y ajenos al medio tucumano. En ese contexto cobró relevancia en el tablero político bellavisteño Fernando Riera, cuya designación como juez de paz en enero de 1944 constituyó el punto de partida de una dilatada trayectoria, que lo erigió en un personaje clave de la política local. Proveniente de una familia de comerciantes acomodados, Riera sintetizó el perfil de la clase media local consolidada al calor del despegue azucarero pero ajena a la influencia directa de la patronal. Al igual que numerosos exponentes de ese sector, los Riera simpatizaban con el conservadurismo encarnado en el PDN y se identificaban con los valores del catolicismo y el nacionalismo. Estas condiciones influyeron en el nombramiento de Fernando, por entonces un destacado dirigente estudiantil universitario, en el mencionado cargo. ${ }^{58}$

Los cambios en el mapa de poder local introducidos durante el gobierno militar y el empoderamiento de actores ajenos a la influencia de la patronal convergieron con la crisis del partido radical, procesos que socavaron el liderazgo de García Fernández. El desalojo del gobierno y el

56 Trópico, Tucumán, 30 de marzo de 1948.

57 El peronismo reunió dirigentes de diversas vertientes políticas e ideológicas, que abarcaron a sindicalistas, radicales, conservadores y nacionalistas católicos. En las diferentes provincias esta amalgama asumió modalidades propias, primando en Tucumán el peso de la rama sindical. Aelo, 2012, 51-82. Prol, 2012, cap. IV.

58 Fernando Riera (1915-1988) era hijo de un comerciante catalán radicado en Bella Vista a fines del siglo diecinueve. Tras cursar los estudios secundarios en el colegio Nacional Bartolomé Mitre, ámbito de formación de la clase dirigente tucumana, inició la carrera de abogacía en la Universidad Nacional de Tucumán. Las oportunidades abiertas por el golpe de Estado lo inclinaron a abandonar los estudios y volcarse a la política. Valeros y Salazar, 2012, 221-37. 
clima de ideas refractario al ciclo político cerrado en 1943 recrudecieron las críticas hacia el radicalismo y, en este contexto, uno de los blancos privilegiados fueron los industriales. Las impugnaciones a este sector también nacieron del propio seno partidario, la presencia de los empresarios en el partido fue cuestionada y, a tono con el clima de polarización política y social de 1945, su marginación se convirtió en leitmotiv del propio radicalismo. ${ }^{59}$ Las demandas de recambio dirigencial orientadas a promover la inclusión de afiliados desvinculados del poder azucarero, visibles desde los años treinta y amplificadas en el nuevo escenario, marcaron el pulso partidario. Sumida en este debate interno, la UCR tucumana atravesó el período comprendido entre la prohibición de los partidos y el inicio de la campaña electoral (enero de 1944 a noviembre de 1945) en un estado de quietud que repercutió en los departamentos agroindustriales. En contraste con la febril actividad desarrollada por los dirigentes peronistas, en las zonas de concentración de ingenios el radicalismo sufrió un sensible desgranamiento. La pérdida de apoyos de la UCR en los distritos azucareros se reflejó en la fuerte caída de afiliados que participaron en las elecciones internas en diciembre de $1945 .{ }^{60}$

En este clima de polarización política y crisis partidaria, García Fernández y sus hombres de confianza se mantuvieron al margen de la vida pública local. Su vuelta al ruedo se produjo a fines de 1945, con motivo de la definición de las autoridades y listas de candidatos de la UCR frente a las inminentes elecciones de febrero de 1946. En el marco de una disputa que trascendió el cauce político para traducir un conflicto social, cifrado en el apoyo de las patronales a la Unión Democrática ${ }^{61}$ y la sólida presencia sindical en el peronismo, tanto García Fernández como los demás industriales radicales fueron objeto de fuertes impugnaciones en las reuniones y actos proselitistas. La Convención Provincial abocada a definir las autoridades de la UCR se desarrolló en un clima plagado de acusaciones cruzadas y cuestionamientos a los propietarios de ingenios, a quienes se procuró marginar del entramado partidario. ${ }^{62}$

59 Lichtmajer, 2014, 90.

60 La participación en Famaillá descendió a 489 afiliados, cifra que contrastó con los 2.935 votantes de 1934. Tucumán, 26 de diciembre de 1945, Archivo Privado de Carlos Orozco (APCO), Libro de actas de la Convención Provincial de la Unión Cívica Radical de Tucumán (1945-1953), 2.

61 La Unión Democrática fue la alianza electoral sostenida en 1946 por la UCR y los partidos Socialista, Comunista y Demócrata Progresista. Se enfrentó a los partidos Laborista y UCR Junta Renovadora, que impulsaron la candidatura de Juan D. Perón.

62 La Gaceta, Tucumán, 26 de diciembre de 1945. 
Desafiados por las organizaciones de obreros y empleados, objetados por sus correligionarios y conmovidos por la avanzada del Estado en la esfera laboral, García Fernández y sus hombres de confianza se desmarcaron de la escena política y sustrajeron su participación en las filas radicales. En la campaña electoral de 1946 el empresario y los empleados jerárquicos del ingenio rehuyeron la presencia en los actos proselitistas del partido radical, tal como sucedió al pasar por el pueblo el «Tren de la Democracia», vehículo que trasladaba a dirigentes de la Unión Democrática. Dichas ausencias fueron resaltadas por los medios, que advirtieron la escasa presencia de afiliados y simpatizantes radicales en un pueblo tradicionalmente alineado con ese partido. Los contrastes con las campañas electorales previas a 1943 también se vislumbraron en la ausencia de comités radicales en el circuito. ${ }^{63}$

Cabe señalar que el abandono partidario de García Fernández y sus allegados, que perduró a lo largo del período analizado, no minó su capacidad para defender sus intereses corporativos ante el Estado. Así lo reflejó la política azucarera impulsada por el gobierno peronista, caracterizada por un profundo involucramiento del Estado nacional en la agroindustria, una de cuyas expresiones fue la política crediticia destinada a los ingenios. En ese marco, Bella Vista fue uno de los establecimientos más favorecidos por los créditos del Banco Industrial y del Banco de la Nación Argentina. ${ }^{64}$ En efecto, puede afirmarse que el retraimiento de García Fernández no carecía de pragmatismo al combinar el abandono del protagonismo político con la obtención de beneficios estatales y la cordial la relación con las autoridades provinciales y nacionales.

El impacto del cuestionamiento al liderazgo político patronal, el empoderamiento obrero y la preeminencia de actores ajenos al organigrama del ingenio constituyen elementos clave para comprender los cimientos del peronismo bellavisteño. Sus primeros balbuceos nos revelan un movimiento de contornos imprecisos que construyó sobre la marcha sus fronteras, jerarquías y tradiciones. Durante este período embrionario pueden identificarse algunas líneas del conflicto entre las redes políticas apuntaladas desde la burocracia estatal por Riera y las que construyó, desde el sindicato, el dirigente obrero Felipe Sosa. Delineada a partir de 1945 con la formación del

63 La Unión, Tucumán, 15 de febrero de 1946.

64 El ingenio Bella Vista fue la segunda fábrica receptora de partidas mayores a un millón de pesos, y a tasa preferencial, otorgada por estos bancos entre 1946-1955. Girbal-Blacha, 2003, 313. También remitimos a Rougier, 2001, 52-60. 
Partido Laborista, ${ }^{65}$ esta disputa evidenció la gravitación de nuevos actores y formas de hacer política que modelaron el entramado de poder local hasta fines de la década del cuarenta.

$\mathrm{Al}$ igual que cientos de funcionarios estatales a lo largo del país, Riera se adhirió tempranamente a la candidatura presidencial de Perón. Para promocionar su postulación a diputado provincial por el departamento $\mathrm{Fa}$ maillá fundó un centro junto a un grupo de jóvenes bellavisteños con los que compartía un mismo rango etario, redes de parentesco y ámbitos de sociabilidad. Nos referimos a Ramón Bustos ${ }^{66}$ y Amado Juri, ${ }^{67}$ miembros de las redes lideradas por Riera. Su entramado político también abarcó a trabajadores del ingenio, donde su principal aliado fue el obrero calificado Rolando González. La necesidad de contar con este apoyo derivaba del peso cuantitativo adquirido por el sindicalismo en Bella Vista y su creciente relevancia en el juego político local. Asimismo, obedecía a la necesidad de hacer frente a los dirigentes gremiales que le disputaban el liderazgo en las filas peronistas. ${ }^{68}$ Precisamente, el principal contendiente de Riera en el seno del movimiento político en ciernes fue Felipe Sosa. Obrero calificado del ingenio, provenía de una familia de afiliados radicales, partícipes de las redes políticas lideradas por García Fernández durante los años treinta. Sosa formó parte del sindicato desde su creación. Sin embargo, su ascenso en la estructura interna gremial, a partir de mayo de 1945, coincidió con su ascendente entre los trabajadores de surco, los cuales constituyeron su principal base de sustento. ${ }^{69}$ En virtud de dicho contexto, el intento de Sosa por liderar el peronismo en Bella Vista fue un hecho a todas luces previsible. Se

65 El Partido Laborista fue creado en octubre de 1945 con el objeto de apoyar la candidatura presidencial de Juan D. Perón. Fue disuelto en mayo de 1946 al formarse el Partido Peronista (inicialmente denominado Partido Único de la Revolución Nacional), organización que pervivió hasta el golpe de Estado de 1955.

66 Nacido en Bella Vista en 1918, Bustos fue hijo de un obrero calificado del ingenio. Transitó un camino formativo equivalente al de Riera: estudió en el colegio Nacional Bartolomé Mitre (Tucumán), tras lo cual se graduó de abogado en 1946. Gómez, 1953, 95.

67 Amado Juri nació en Bella Vista en 1916. Casado con una hermana de Riera, fue dirigente de la filial bellavisteña del Sindicato de Obreros y Empleados de Comercio en los inicios del peronismo. Morales Solá, 2005, 54.

68 Al visibilizar la mixtura entre la dirigencia proveniente de los ámbitos sindical y estatal, las redes partidarias aquí descritas contribuyen a matizar la distinción entre «sindicalistas» y «políticos» planteada en el pionero trabajo de Moira Mackinnon en relación a la formación del Partido Peronista. Mackinnon, 2002, 50-59. En ese sentido, este texto recupera la observación de Nicolás Quiroga sobre las limitaciones de dicha distinción para aprehender la conflictividad en las escalas inferiores de la estructura partidaria peronista. Quiroga, 2010, 19.

69 Acta 20, 13 de mayo de 1945, APMV, Libro de Actas del Sindicato de Obreros del Ingenio Bella Vista (1944-1947), 48. 
trató, por cierto, de una actitud que los dirigentes gremiales bellavisteños compartieron con sus pares de los ingenios tucumanos, definida acertadamente por Gustavo Rubinstein como una «búsqueda del exclusivismo gremial y político». ${ }^{70}$ Con ese fin, Sosa se rodeó de un grupo de referentes de peso entre los trabajadores - tales como Andrés Paliza, vicepresidente del sindicato, y Antonio Salas, prosecretario- y los empleados, entre los que se destacó Nicolás Socci, ex médico del ingenio. ${ }^{71}$

El salto del campo gremial al partidario estuvo lejos de ser una tarea sencilla para Sosa y sus lugartenientes sindicales. Dicho pasaje los obligó a posicionarse en el complejo mapa de fracciones y grupos que pugnaban en el seno del emergente movimiento político que impulsaba la candidatura presidencial de Perón. Las filas peronistas de Tucumán se quebraron en enero de 1946 con la proclamación de dos candidaturas para gobernador. Por un lado, la de Enrique Thiele (Partido Laborista de Tucumán), abogado a cargo de la Dirección General de Rentas de la Provincia; y, por el otro, la de Carlos Domínguez (Partido Laborista), militar retirado, oriundo de Buenos Aires y ex secretario general de la Intervención Federal (1943). ${ }^{72}$ Riera y sus aliados bellavisteños apoyaron la candidatura de Domínguez. Por su parte, las huestes lideradas por Sosa se mostraron reacias a ponerse bajo la tutela de Riera y el grupo de jóvenes que lo secundaban, volcándose hacia Thiele. Para contrarrestar la creciente influencia de Riera en el circuito y apuntalar las candidaturas de Sosa y Socci a diputados, dichos jóvenes formaron un centro político a comienzos de $1946 .{ }^{73}$

Los ecos de la disputa al interior del peronismo bellavisteño signaron el derrotero del sindicato. Los trabajadores aliados con Riera, liderados por González, emprendieron una campaña de denuncias contra la comisión directiva e incitaron a la desobediencia a los obreros de surco. Las autoridades fotianas reaccionaron enérgicamente: expulsaron del sindicato a los responsables y consiguieron que la administración del ingenio los suspendiera en sus funciones. ${ }^{74}$ Mientras que la pulseada al interior del sindicato se volcó hacia Sosa, las tensiones en torno a la conducción local del peronismo se dirimieron a favor de Riera. En este desenlace tuvo un peso sustancial la intervención de Perón, quien manifestó públicamente su

70 Rubinstein, 2006, 33.

71 Empleados superiores del ingenio, 1939, APARZ, Compañía azucarera Bella Vista.

72 La Gaceta, Tucumán, 13 de enero de 1946.

73 Ibidem, 3 de febrero de 1946.

74 Acta 27, 31 de enero de 1946, APMV, Libro de Actas del Sindicato de Obreros del Ingenio Bella Vista (1944-1947), 82-85. 
apoyo a la candidatura de Domínguez en febrero de 1946. La palabra del líder partidario persuadió a los dirigentes gremiales bellavisteños a resignar sus aspiraciones y a abandonar la lista de Thiele con el fin de fortalecer la nómina bendecida por aquel.

A pesar de estos gestos de acercamiento, las represalias provocadas por la estrategia inicial no se hicieron esperar. En las listas departamentales del Partido Laborista no se incluyó a representantes del Bella Vista, priorizándose a delegados de establecimientos de menor porte como Mercedes y Nueva Baviera. ${ }^{75}$ Aunque se trató de un desenlace previsible, a la luz del derrotero seguido por las autoridades gremiales, esta decisión no pasó desapercibida para los trabajadores bellavisteños, que se resistieron a resignar el liderazgo político en manos de Riera. Así lo expresaron en el masivo acto de proclamación de los candidatos peronistas en Bella Vista, del que tomó parte la plana mayor de la filial tucumana del partido. Cuando González, principal aliado de Riera, profería un discurso, un numeroso grupo de trabajadores coreó el nombre de Sosa y reclamó su inclusión en la lista legislativa. A pesar del pedido de Domínguez de abandonar tal actitud, reclamar que no se agraviara a «la cultura, la bandera nacional y al coronel Perón» e invitar a Sosa a ocupar el palco, la concurrencia siguió en su tesitura y el acto debió suspenderse. ${ }^{76}$

Puestos crudamente en escena durante la campaña electoral, los conflictos que acompañaron la emergencia del peronismo en el campo político bellavisteño, derivados principalmente de la disputa por el liderazgo de las filas locales del partido, introdujeron un elemento poco habitual en el período analizado. Aunque en las campañas electorales de los años treinta no faltaron los enfrentamientos entre grupos, el liderazgo de la patronal, permeado por el paternalismo, delimitó y atenuó los conflictos, impregnando a la dinámica local de cierta contención que se resquebrajó con la irrupción del peronismo. Lejos de representar un signo de debilidad, esta impronta conflictiva, en constante estado de ebullición, remitía a un movimiento magmático que se encontraba en franca expansión a nivel local. En contraste con un radicalismo replegado, que no fundó organismos de base en vista de los comicios de febrero de 1946, el peronismo bellavisteño

75 Los candidatos del Partido Laborista por el departamento Famaillá fueron los siguientes: electores de gobernador: Marcos Campos, Héctor Morales, Manuel Santiago, Javier Leiva, Luis Castro, Ernesto Luna; senadores provinciales: Delfor Gallo, Ernesto Luna; diputados provinciales: Juan González, Fernando Riera, Manuel Osores, Luis Castro. La Gaceta, Tucumán, 24 de febrero de 1946.

76 La Gaceta, Tucumán, 18 de febrero de 1946. 
intervino en el espacio público a través de centros filiados en las dos fracciones opositoras.

Los resultados electorales escenificaron el reacomodo del campo político local. Si hasta 1943 Bella Vista había sido un bastión electoral de las redes patronales, los comicios de febrero de 1946, que marcaron el acceso del peronismo al poder, confinaron a la UCR a un lugar periférico. La candidatura presidencial de Perón logró en el circuito 2.181 sufragios (88 por ciento) contra 286 (12 por ciento) de la Unión Democrática, encabezada por el radicalismo pero de la que García Fernández se mantuvo distante. La conquista de un porcentaje de votos lindante al 90 por ciento superaba todas las marcas alcanzadas por la patronal durante la etapa previa. El descenso del voto radical en Bella Vista rebasó los pronósticos más pesimistas de la prensa, que confesó su perplejidad ante la vertiginosa caída del otrora partido dominante. Un periodista del principal diario provincial señaló que si bien el proceso de organización sindical hacía prever un triunfo peronista en Bella Vista, la contundencia del resultado llamaba la atención, en razón del pasado radical del circuito. ${ }^{77} \mathrm{El}$ descalabro electoral fue aun más acentuado en el caso del conservadurismo, que cerró su ciclo político en la localidad durante varios lustros. Los partidos de izquierda (PS, Partido Comunista), por su parte, mantuvieron una presencia limitada en el circuito. ${ }^{78}$

El fuerte apoyo popular a las candidaturas peronistas fortaleció la figura de Riera en el tablero político local. Su elección como diputado (1946) lo convirtió en el único bellavisteño que logró un sitial en las cámaras legislativas provinciales en los años iniciales del peronismo. Su febril actividad, plasmada en numerosos proyectos orientados a los vecinos del pueblo, le granjeó numerosos apoyos en la zona. ${ }^{79}$ Asimismo, apuntaló a sus aliados en el renovado entramado local. En tal sentido, Bustos fue designado en 1946 abogado de la Dirección Regional de la Secretaría de Trabajo y Previsión, cargo clave en la relación entre los sindicatos y el Estado, para ejercer entre 1950 y 1952 como ministro de Gobierno. ${ }^{80}$ Paralelamente se desempeñó como presidente del club Sportivo, espacio controlado tradicionalmente por miembros del personal jerárquico del ingenio. ${ }^{81}$ Por su parte, Juri fue designado jefe de la Policía de Tucumán y González vicepresidente

77 Ibidem, 21 de marzo de 1946.

78 Idem.

79 Diario de Sesiones de la Cámara de Diputados de la Provincia de Tucumán (DSCDT), 1946, 15-20.

80 Trópico, Tucumán, 8 de febrero de 1950.

81 Listado de autoridades del Club Sportivo Bella Vista, 1925-2015, APMV. 
de la Comisión de Higiene y Fomento, entidad que presidía el hermano de Bustos (Moisés). ${ }^{82}$ Estas designaciones revelan hasta qué punto impactaron el cambio en las lealtades políticas y la irrupción del peronismo en los planteles locales de gobierno, dominados hasta entonces por funcionarios afines a la patronal.

La construcción de un sólido andamiaje político confluyó, en el caso de Riera, con una estrecha relación con el gobernador Domínguez y con Eva Perón, personajes que coadyuvaron a su proyección en la escena provincial. En su afianzamiento contribuyó, asimismo, la definición de la puja sindical sintetizada en el desplazamiento de la fracción encabezada por Sosa y la preeminencia del sector afín a Riera. A través de diferentes mecanismos desplegados a lo largo de 1947, que incluyeron desde denuncias de malversación de fondos contra la comisión directiva hasta la creación de un sindicato paralelo, los disidentes lograron acorralar a Sosa y forzar su retirada. Tras denunciar un boicot de Riera, Sosa renunció a la presidencia del sindicato en agosto de $1947 .{ }^{83}$ En las elecciones de autoridades del Partido Peronista, realizadas a los pocos días de su desplazamiento del gremio, Sosa tomó parte en la lista opositora a Riera, intentona que también resultó en vano. ${ }^{84}$ Por entonces, la figura del diputado estaba en franco crecimiento en la política provincial. En 1948 fue designado ministro de Gobierno, cargo que ejerció hasta 1950 cuando encabezó la candidatura a gobernador de la provincia, siendo electo por amplia mayoría. Ocupó la primera magistratura hasta 1952, para luego desempeñarse como senador nacional $(1952-1955){ }^{85}$

Como contrapartida, el desplazamiento del radicalismo se profundizó hacia finales de la década de 1940. En las elecciones internas de enero de 1948 votaron en Bella Vista tan solo 19 afiliados, cifra irrisoria si se la compara con los 1.286 que tomaron parte en 1934. El desmembramiento del radicalismo bellavisteño se reeditó en las elecciones legislativas de marzo de 1948, al reducirse su caudal a solo 145 votos contra 2.313 de las fracciones peronistas. Esto llevó a un medio local a concluir que, en contraste con la avalancha de sufragios que cosechó el radicalismo en el circuito hasta 1943, en esta oportunidad «ni siquiera los fiscales» votaron por el partido. De esto de 1999.

82 Entrevista a Rolando González realizada por Atilio Santillán, Bella Vista, 30 de octubre

83 En su lugar se designó como interventor a Rolando González. Trópico, Tucumán, 7 de agosto de 1947.

84 Ibidem, 23 de septiembre de 1947

85 Valeros y Salazar, 2012, 221-37. 
se desprendía una conclusión categórica: ni los empleados superiores del ingenio respondían a «sus viejos ideales políticos». ${ }^{86}$

\section{Consideraciones finales}

A mediados de la década de 1940 el pueblo azucarero de Bella Vista experimentó una sensible transformación política, cuya expresión más nítida fueron los resultados electorales, en los que el arrasador triunfo peronista dejó atrás años de hegemonía radical. El contraste visibilizado en el cambio en las lealtades partidarias locales implicó cambios en las prácticas políticas, promovió la construcción de nuevas redes y liderazgos, alentó la irrupción de actores organizados más allá de la mirada empresarial y generó renovadas instancias de conflictividad y consenso.

La transición del radicalismo al peronismo supuso nuevas formas de hacer política que ganaron en autonomía frente a la patronal. Este proceso fue consustancial a una creciente politización local expresada en la participación de los trabajadores y de los sectores medios, que adquirieron un inusitado protagonismo no exento de conflictos. El aliento gubernamental a la sindicalización obrera, el recambio del funcionariado estatal y el reconocimiento de derechos que horadaron las prerrogativas empresariales modelaron la trayectoria del peronismo, impactaron en la urdimbre tejida por la patronal y, por ende, contribuyeron a desarticular el predominio radical. Esta dinámica promovió nuevas prácticas políticas, que recuperaron experiencias y tradiciones previas. En tal sentido, el desplazamiento de los industriales de la política local se potenció con los cuestionamientos devenidos del propio seno partidario que, entre las estrategias desplegadas para enfrentar al peronismo, buscó la marginación y estigmatización de los empresarios azucareros. La convergencia de obreros y sectores medios en la política bellavisteña generó nuevos entramados, inescindibles de una construcción de poder asociada a la expansión territorial del peronismo, promoviendo una inusitada conflictividad social que marcó el pulso de dinámica local. Estas tensiones expresaron el proceso de incertidumbres y posibilidades en el que fueron definiéndose los contornos sociales y proyecciones políticas del naciente movimiento peronista.

En síntesis, revisitar el pueblo de Bella Vista en la transición del radicalismo al peronismo permitió repensar sentidos historiográficos asociados

86 Trópico, Tucumán, 15 de marzo de 1948. 
a los partidos de masas argentinos desde espacios e interrogantes que ocuparon un lugar marginal en las investigaciones. La localización de este proceso en una comunidad laboral azucarera del interior argentino complejizó el predominante tinte urbano de los estudios históricos al recuperar las diversas prácticas políticas del radicalismo, en este caso, las propias del ámbito agroindustrial. Asimismo, la reducción de la escala local de observación nos devolvió la densidad de la conflictividad inherente al peronismo y su impacto en la construcción de liderazgos y las formas de hacer política, procesos inescindibles del protagonismo sindical azucarero en la emergencia del nuevo movimiento. De ese modo, la perspectiva de análisis en el cruce de la especificidad local y las tendencias generales del derrotero nacional posibilitó recuperar el anclaje social de la política, distanciándonos de concepciones per se que desdibujaron el protagonismo de los actores y opacaron las formas de construcción, conflicto y negociación propias de dicha instancia.

Recibido el 13 de enero de 2016 Aceptado el 21 de abril de 2016

\section{Referencias bibliográficas}

Aelo, Oscar H., El peronismo en la provincia de Buenos Aires (1946-1955), Caseros, EDUNTREF, 2012.

Bohoslavsky, Ernesto y Caminotti, Daniel, «El peronismo y el mundo rural norpatagónico. Trabajo, identidad y prácticas políticas», en Masés, Enrique y Rafart, Gabriel (dirs.), El peronismo, desde los territorios a la nación. Su historia en Río Negro y Neuquén, 1943-1958, Neuquén, Universidad Nacional del Comahue, 2003, 79-104.

Bonaudo, Marta, «Presentación. La cuestión regional», en Bandieri, Susana; Blanco, Graciela y Blanco, Mónica (coords.), Las escalas de la historia comparada. Empresas, empresarios y cuestión regional, Buenos Aires, Miño y Dávila, 2008, 227-231.

Bravo, María Celia, «Liberales, socialistas, Iglesia y patrones frente a la cuestión de los trabajadores en Tucumán», en Suriano, Juan (comp.), La cuestión social en Argentina, 1870/1943, Buenos Aires, La Colmena, 2000, 31-61.

Campi, Daniel, «Economía y sociedad en las provincias del norte», en Lobato, Mirta (dir.), El progreso, la modernización y sus límites 1880-1916, Buenos Aires, Sudamericana, 2000, 71-118.

Campi, Daniel, «Contrastes cotidianos. Los ingenios del norte argentino como complejos socioculturales, 1870-1930», Varia Historia, 25, 41, Belo Horizonte, 2009, 245-267. 
Fernández de Ullivarri, María, «Sindicatos en la “capital del azúcar”. Organización y lucha en el mundo del trabajo de la provincia de Tucumán (Argentina). 1930-1943», Historia Agraria. Revista de Agricultura e Historia Rural, 55, Murcia, 2011, 105-37.

Fradkin, Raúl y Gelman, Jorge, «Recorridos y desafíos de una historiografía. Escalas de observación y fuentes en la historia rural rioplatense», en Bragoni, Beatriz (comp.), Microanálisis: Ensayos de Historiografía argentina, Buenos Aires, Prometeo, 2004, 31-54.

Girbal-Blacha, Noemí, «Economía azucarera tucumana, empresarios y crédito en tiempos del Estado peronista (1946-1955)», en Macor, D. y Tcach, C. (eds.), La invención del peronismo en el interior del país, Santa Fe, Universidad Nacional del Litoral, 2003, 265-371.

Gómez, Mario, Tucumán sus bellezas y sus personalidades, Buenos Aires, Federación Gráfica Argentina, 1953.

Gutiérrez, Florencia y Rubinstein, Gustavo (comps.), El primer peronismo en Tucumán. Avances y nuevas perspectivas, Tucumán, Universidad Nacional de Tucumán, 2012.

Guy, Donna, Política azucarera argentina. Tucumán y la generación del ochenta, Tucumán, Universidad Nacional de Tucumán, 2008.

Horowitz, Joel, «Patrones y clientes: el empleo municipal en el Buenos Aires de los primeros gobiernos radicales (1916-1930)», Desarrollo Económico, 46, 184, Buenos Aires, 2007, 569-596.

Kindgard, Adriana, Alianzas y enfrentamientos en los orígenes del peronismo jujeño. San Salvador de Jujuy, Universidad Nacional de Jujuy, 2009.

Landaburu, Alejandra, «Los empresarios azucareros y la cuestión social. Tucumán, 1904-1930», Tesis de doctorado, Universidad Nacional de Tucumán, 2014.

Lichtmajer, Leandro, «Discursos, prácticas y estrategias políticas del radicalismo tucumano (1943-1956)», Tesis de doctorado, Universidad Nacional de Tucumán, 2012.

Lichtmajer, Leandro, «Operando sobre la coyuntura. Inflexiones en las vías de financiamiento de la Unión Cívica Radical de Tucumán durante el primer peronismo», en Mauro, Diego y Lichtmajer, Leandro (comps.), Los costos de la política. Del Centenario al primer peronismo, Buenos Aires, Imago Mundi, 2014, 81-97.

Lichtmajer, Leandro; Gutiérrez, Florencia y Santos Lepera, Lucía, «La comunidad laboral del ingenio Bella Vista. La resignificación de la experiencia obrera en los inicios del peronismo», Anuario de Historia Regional y de las Fronteras, 21, 1, Bucaramanga, 2016, 213-236.

Lobato, Mirta, La vida en las fábricas. Trabajo, protesta y política en una comunidad obrera, Berisso (1904-1970), Buenos Aires, Prometeo, 2004.

Mackinnon, Moira, Los años formativos del Partido Peronista (1946-1950), Buenos Aires, Instituto Di Tella, Siglo Veintiuno de Argentina Editores, 2002. 
Macor, Darío y Tcach, César (eds.), La invención del peronismo en el interior del país, Santa Fe, Universidad Nacional del Litoral, 2003.

Morales Solá, Hugo, Amado Juri. Gladiador de la democracia, Tucumán, Lucio Piérola Ediciones, 2005.

Moyano, Daniel, «Firmas familiares, empresariado e industria azucarera en Tucumán, 1895-1945», Tesis de doctorado, Universidad Nacional de Tucumán, 2011.

Parra, María Graciana, «Blancos, demócratas y radicales en la encrucijada de los años treinta. El impuesto adicional al azúcar, Tucumán 1932-1934», Travesía, 13, Tucumán, 2011, 127-162.

Posada Carbó, Eduardo, «Electoral Juggling: A Comparative History of the Corruption of Suffrage in Latin America, 1830-1930», Journal of Latin American Studies, 32, 3, Cambridge, 2000, 611-644.

Prol, Mercedes, Estado, movimiento y partido peronista. La ingeniería institucional en Santa Fe, 1943-1955, Buenos Aires, Siglo Veintiuno Editores, 2012.

Quiroga, Nicolás, «La dimensión local del Partido Peronista. Las unidades básicas durante el primer peronismo, Mar del Plata (1946-1955)», Tesis de doctorado, Universidad Nacional de Mar del Plata, 2010.

Rein, Raanan, «De los grandes relatos a los estudios de pequeña escala: algunas notas acerca de la historiografía del primer peronismo», Temas de Historia Argentina y Americana, 14, Buenos Aires, 2009, 133-65.

Revel, Jacques, «L'histoire au ras du sol», en Levi, Giovanni, Le pouvoir au village. Histoire d'un exorciste dans le Piémont du XVII siècle, Paris, Gallimard, 1989, I-XXXIII.

Rock, David, El radicalismo argentino, 1890-1930, Buenos Aires, Amorrortu, 1977.

Rougier, Marcelo, La política crediticia del Banco Industrial durante el primer peronismo, 1944-1955, Buenos Aires, Centro de Estudios Económicos de la Empresa y el Desarrollo, 2001.

Rubinstein, Gustavo, Los sindicatos azucareros en los orígenes del peronismo tucumano. Tucumán, Universidad Nacional de Tucumán, 2006.

Schleh, Emilio, Compilación legal sobre el azúcar, XIII, Buenos Aires, Imprenta Ferrari, 1947.

Taboada, María y Lobo, Héctor, Los dueños de la zafra, Tucumán, Universidad Nacional de Tucumán, 1996.

Unión Cívica Radical, Distrito de Tucumán, Carta Orgánica, Tucumán, Editorial La Raza, 1941.

Valeros, Manuel y Salazar, Antonio, Notas sobre la historia de Bella Vista, Tucumán, Universidad Nacional de Tucumán, 2012. 